\title{
Aplicação de nanotecnologia em embalagens de alimentos
}

\section{Application of nanothecnology in food packaging}

\author{
Ana Carolina Sergio Almeida ${ }^{1}$, Elisângela Aparecida Nazário Franco ${ }^{1}$, Fernanda Marques Peixoto ${ }^{1 *}$ \\ Kênia Letícia Ferreira Pessanha ${ }^{1}$ e Nathália Ramos Melo ${ }^{1,2}$ \\ 'Programa de Pós-graduação em Ciência e Tecnologia, Departamento de Tecnologia, \\ Universidade Federal Rural do Rio de Janeiro - UFRRJ, Rio de Janeiro, RJ, Brasil \\ ${ }^{2}$ Departamento de Engenharia do Agronegócio, Universidade Federal Fluminense - UFF, \\ Volta Redonda, RJ, Brasil \\ *fpeixoto24@gmail.com
}

\begin{abstract}
Resumo
A nanotecnologia tem grande potencial de aplicação na indústria de alimentos. No desenvolvimento de embalagens, pode proporcionar diferentes alternativas, tais como o desenvolvimento de nanopartículas, nanodispersões, nanolaminados, e nanotubos, que, associados aos polímeros, podem fornecer diversas funções. Por exemplo, pela incorporação de nanopartículas com propriedades antimicrobianas; nanosensores capazes de detectar produtos químicos, agentes patogênicos e toxinas em alimentos; nanopartículas bioativas capazes de manter os compostos em condições ideais, até a sua migração para o produto alimentício e nanocompósitos, que melhorem as propriedades de flexibilidade, barreira a gases e umidade e quanto à absorção de irradiação UV dos materiais aos quais são incorporados, assim como a estabilidade frente à temperatura. Este artigo relata algumas aplicações da nanotecnologia em embalagens de alimentos, bem como questões sobre toxicidade e regulamentação relacionadas à possibilidade de migração das nanopartículas para os alimentos; razão pela qual o setor alimentício tem sido cauteloso com a utilização desses materiais.
\end{abstract}

Palavras-chave: toxicidade, regulamentação, nanoparticulas, embalagem ativa, embalagem inteligente.

\begin{abstract}
Nanotechnology has great application potential in the food industry. In packaging development, it can provide several alternatives, such as the formation of nanoparticles, nanodispersions, nanolayered and nanotubes, which, associated with polymers, can provide multiple functions. For example, by embedding nanoparticles with antimicrobial properties; nanosensors capable of detecting chemicals products, pathogens and toxins in food; bioactive nanoparticles capable of maintaining compounds at optimal conditions until its migration to the food product and nanocomposites, which improve the properties of flexibility, gas and humidity barrier and UV irradiation absorption of the materials to which are incorporated, as well as stability against temperature. This article reports some applications of nanotechnology in food packaging, as well as questions regarding toxicity and regulations related to the migration of nanoparticles to the food products; reason why the food industry has been cautious with the utilization of these materials.
\end{abstract}

Keywords: toxicity, regulation, nanoparticles, active packaging, intelligent packaging.

\section{Introdução}

Atualmente, grande parte das embalagens utilizadas no setor alimentício é de plástico, produzidas com base em polímeros oriundos do petróleo. Em geral, na comparação com outros materiais como papel, madeira, metais, vidros e cerâmicas, as embalagens plásticas destacam-se pelas vantagens que apresentam quanto às características físico-mecânicas como peso, flexibilidade, resistência mecânica, bem como outras características físico-químicas e biológicas, vinculada à qualidade, saúde e segurança, algumas das quais serão abordadas mais adiante. Em conjunto, essas características além de proporcionarem vantagens significativas no processamento de embalagens e adição de valor aos produtos que acondicionam, produzem também reduções de custo de produção e redução dos preços aos consumidores ${ }^{[1]}$.
A nanotecnologia é uma ciência relativamente nova, tal conceito foi proposto na década de 60 e o avanço na área tem sido gradual ${ }^{[2]}$, estendendo-se até o presente com significativa participação da biotecnologia. Participação esta que, apesar de apresentar grandes vantagens, traz muitas incertezas referentes à migração destas partículas manométricas das embalagens para o alimento, bem como a sua absorção e comportamento no organismo humano, nos animais e no meio ambiente. Esta temática em geral traz muitas dúvidas aos consumidores e aos órgãos de regulamentação, que ainda dependem de futuros estudos.

Assim, o presente artigo objetiva relatar algumas aplicações da nanotecnologia no desenvolvimento de 
embalagens para produtos alimentícios, bem como questões sobre a toxicidade e regulamentação relacionada à migração de nanopartículas para os alimentos.

\section{Metodologia}

A metodologia constituiu-se do levantamento bibliográfico realizado através da consulta das principais Bases de Dados de circulação internacional, tais como Web of Science, Science Direct e Web of Knowledge. As palavras chave utilizadas foram: nanothecnology, packaging, application e food. Além disso, foram consultados artigos publicados em português, no Google Acadêmico e na base de dados Scielo. Informações do Ministério da Saúde publicadas na internet também foram utilizadas.

A estrutura do relato limitou-se a apresentar informações circunscritas à adição de cargas aos polímeros usados em embalagens nanotecnológicas genericamente classificadas como: embalagens aprimoradas; embalagens ativas; embalagens bioativas e embalagens inteligentes, complementadas com informações relacionadas a questões sobre toxicidade e regulamentação.

\section{Resultados e Discussão}

\subsection{Adição de cargas em polímeros}

No ano de 1960, os materiais poliméricos eram considerados caros. Objetivando baixar os custos de manufatura, os fabricantes passaram a utilizar cargas minerais fibrosas ou particuladas, de baixo custo, no seu desenvolvimento. O método se propagou de tal maneira que o uso de cargas, termo técnico como ficou conhecido esse tipo de recurso na produção de polímeros, tornou-se frequente, pois estas cargas fornecem corpo e conferem novas propriedades aos materiais. A adição de cargas (fase dispersa/descontínua) à matriz polimérica (fase contínua) origina um novo material com características diferentes, denominado compósito. A matriz polimérica tem a função de manter a integridade estrutural do compósito, em virtude das suas propriedades de coesão, já a fase dispersa desempenha o papel de transferir tensões que, por sua vez, atuam como um reforço ou enchimento do material, conferindo um melhor desempenho mecânico da matriz, portanto, modificando suas propriedades. Entretanto, essa adição de cargas à matriz polimérica também promove impactos negativos como: diminuição da resistência ao impacto, menor resistência à tração, maior densidade e maior rigidez ${ }^{[2]}$ que precisam ser controlados.

Para que a carga forneça resistência ao polímero, é necessário que haja o controle das propriedades físico-químicas na interação da carga com a matriz e, caso esta interação não seja adequada, o produto final será frágil. É necessária uma boa dispersão das partículas na matriz, de forma que as cargas não fiquem agregadas, dificultando a interação com a matriz polimérica, o que afeta as propriedades mecânicas, através da concentração de tensão. Portanto, a resistência final é dependente do tamanho da partícula, pois o tamanho da carga determina a área de contato e a resistência aumenta com a diminuição do tamanho da partícula $^{[2]}$. Desta forma, Alexandre \& Duboi ${ }^{[3]}$ justificam a utilização das nanopartículas no desenvolvimento de nanocompósitos, sendo estes os novos materiais bifásicos; compostos híbridos incorporados à matriz polimérica, com pelo menos uma de suas fases em escala manométrica na faixa entre 1 e $100 \mathrm{~nm}^{[4]}$, onde a manipulação dos materiais é realizada na escala atômica ${ }^{[5-7]}$. A argila, o cálcio ${ }^{[8]}$, o dióxido de titânio $\left(\mathrm{TiO}_{2}\right)^{[9]}$ e a nanofibra de celulose ${ }^{[10]}$ são exemplos de cargas utilizadas.

Segundo Drexler ${ }^{[11]}$, o conceito da nanotecnologia foi proposto em 1959, por Richard Feynman e desde então, pesquisas indicam que as propriedades de muitos materiais, podem ser melhoradas com a adição de nanocompósitos durante o desenvolvimento ${ }^{[4]}$. Embalagens com aplicações nanotecnológicas adquirem melhores propriedades físico-químicas, redução da hidrofilicidade, além de proporcionar uma melhor biodegradabilidade, o que gera valor agregado aos produtos ${ }^{[12]}$. Tais embalagens podem ser classificadas, genericamente, como: embalagens aprimoradas, cujos nanocompostos podem alterar suas propriedades e aumentar a validade comercial do alimento; embalagens ativas pela adição de nanocompostos, como por exemplo, nanopartículas de óxido metálicos ou de metais com propriedades antimicrobianas; embalagens bioativas, incorporando compostos bioativos capazes de prevenir ou reduzir riscos de doenças e embalagens inteligentes, incorporadas com nanosensores para monitorar e relatar as condições dos alimentos acondicionados ou do ambiente ao redor ${ }^{[13]}$.

Apesar das vantagens, a aplicação da nanotecnologia no setor de embalagens esbarra com sérias questões referentes ao surgimento da toxicidade atribuída ao comportamento das partículas na escala nanométrica. Estas partículas podem migrar das embalagens para o alimento, causando possíveis danos aos consumidores ${ }^{[14]}$ e ao meio ambiente. Logo, a aplicação desta tecnologia demanda de uma regulamentação específica para o setor.

\subsection{Embalagens aprimoradas}

Algumas características críticas das embalagens estão relacionadas com propriedades como flexibilidade, barreira a gases e a umidade, estabilidade térmica e radiação UV do material a ser utilizado ${ }^{[15]}$; bem como outras situações que podem reduzir a validade comercial do alimento embalado e por em risco a saúde do consumidor. Entretanto, estas podem ser monitoradas pela inclusão de sensores que detectam microrganismos patogênicos, micotoxinas e proteínas específicas como a gliadina e glutenina.

\subsubsection{Nanopartículas de celulose}

As nanopartículas de celulose podem existir de duas formas distintas como: microfibrilas e os whiskers, que são partes cristalinas também conhecidas como nanocristais.

Os nanocompósitos podem melhorar as propriedades de barreira à umidade dos polímeros. As fibras cristalinas aumentam a tortuosidade do material em que estão inseridas e conduzem a processos de difusão mais lentos e, desta forma, a permeabilidade é mais lenta ${ }^{[16]}$.

Nanocristais de celulose podem ser adicionados, através de hidrólise ácida, a blenda de poli (ácido lático) (PLA) e poli-hidroxibutirato (PHB) para melhorar suas propriedades finais em sistemas multifuncionais. Para essa incorporação, 
é necessário o uso de surfactantes aos nanocristais de forma a aumentar a adesão interfacial. O resultado da incorporação deste nanocomposto está relacionado a uma maior interação entre PLA e PHB, além de melhorias na estabilidade térmica, demonstrando boa aplicabilidade na indústria de embalagens para alimentos ${ }^{[17]}$

\subsubsection{Argilas e silicatos}

Devido a sua disponibilidade, baixo custo, processamento simples e sua constatada melhoria nas propriedades dos materiais, a argila e o silicato, que são sólidos inorgânicos, vêm ganhando espaço na área de nanotecnologia de embalagens para alimentos. A argila dá origem a plaquetas com elevada superfície de contato $\left(750 \mathrm{~m}^{2} / \mathrm{g}\right)$ e o silicato consiste em camadas bidimensionais de aproximadamente $1 \mathrm{~nm}$ de espessura, dependendo do tipo de silicato usado para revestimento de superfície. Essas nanopartículas aumentam a tortuosidade do caminho difusivo para uma molécula penetrante qualquer. $\mathrm{O}$ caminho pode ser aumentado em função da elevada proporção de material de enchimento e do volume de argila ${ }^{[18]}$.

A combinação de nanocargas adicionadas a biopolímeros, para a produção de bionanocompósitos também tem sido bastante utilizada para melhoria da resistência mecânica, como, por exemplo, em nanocompósito termoplástico de amido e argila $(5 \% \mathrm{~m} / \mathrm{m})$ que conferem ao produto melhores propriedades mecânicas e diminuem a permeabilidade ao vapor de água $^{[19]}$.

O desenvolvimento de nanocompósito de polietileno (PE) adicionado de 35\% de nano-prata, $40 \%$ de dióxido de titânio e $25 \%$ de montmorilonita (MMT) e sua aplicação na qualidade pós-colheita de kiwis, foi avaliado e verificou-se que houve uma diminuição significativa da permeabilidade ao vapor d'água, como também do amadurecimento do kiwi, prolongando sua validade comercial. Além disso, os frutos apresentaram baixa atividade da polifenoloxidase e alta atividade da peroxidase quando comparado ao controle (apenas PE). Estas enzimas são responsáveis pelo processo de escurecimento em frutas e vegetais ${ }^{[20]}$.

\subsubsection{Dióxido de titânio}

Uma alternativa para solucionar o problema da susceptibilidade a fotodegradação pela radiação ultravioleta (UV) do filme de polipropileno biorientado é a incorporação de nanocompostos de dióxido de titânio $\left(\mathrm{TiO}_{2}\right.$, que são estabilizadores deste tipo de radiação em polímeros devido a sua capacidade semi-condutora ${ }^{[21]}$. Estudos relatam que após 6 semanas de análises, o revestimento conseguiu impedir a formação de grande parte da fotodegradação que ocorria nos filmes sem o revestimento de $\mathrm{TiO}_{2}$, comprovando a eficácia de sua utilização em embalagens de alimentos ${ }^{[22]}$. A atividade fotocatalítica do $\mathrm{TiO}_{2}$ está vinculada com a sua estrutura cristalina e pode apresentar-se de três formas distintas: anatase, tetragonal ou ortorrômbica, apresentando, desta forma, reatividades diferentes ${ }^{[23]}$.

\subsubsection{Nanotubos de carbono}

Os nanotubos de carbono (NTC) podem apresentar-se com um único átomo de espessura de parede, ou em número maior de tubos concêntricos chamados nanotubos multiparedes, e quando adicionados a polímeros, mesmo em baixas concentrações, podem melhorar as propriedades mecânicas, de barreira e aumentar a estabilidade térmica ${ }^{[24]}$.

Shan et al. ${ }^{[25]}$ avaliaram a adição de NTC com elevado modo de elasticidade a poli (3-hidroxibutirato) -co- (3-hidroxivalerato) (PHBV), e verificaram melhorias significativas no comportamento térmico e de cristalização, além de melhorias nas propriedades mecânicas, elétrica e de barreira a gases da matriz ${ }^{[26]}$. Filmes transparentes a luz visível, também puderam ser obtidos através dessa incorporação, apresentando boa dispersibilidade na matriz, excelente resistência à tração e a boa elasticidade. Com essas características, estes filmes têm elevado potencial para aplicação em embalagens de alimentos e bebidas ${ }^{[27]}$.

Estudos sobre os efeitos da orientação das partículas, da taxa de deformação e do conteúdo volumétrico, realizados em nanocompósitos baseados em nanotubos de carbono de parede única e polipropileno (PP), demonstraram haver melhorias nas propriedades mecânicas, mesmo a baixas concentrações $^{[28]}$.

\subsection{Embalagens ativas pela adição de Nanocomposto}

Uma série de materiais metálicos em nanoescala tem sido estudados devido as suas propriedades antimicrobianas. Entre estes compostos incluem-se nanopartículas à base de óxido de magnésio, óxido de cobre, óxido de zinco, seleneto de cádmio/telureto, dióxido de titânio e prata ${ }^{[29-31]}$.

A vantagem dos agentes antimicrobianos de prata, é que estes podem ser facilmente incorporados a vários materiais, tais como plásticos e têxteis, tornando-se úteis para aplicações com um amplo espectro, mantendo sua atividade antimicrobiana, onde antimicrobianos tradicionais seriam instáveis ${ }^{[32]}$.

Desde os primeiros relatos, publicados sobre as propriedades antimicrobianas dos coloides de prata, as nanopartículas de prata (AgNP) têm sido estudadas como sendo potentes agentes contra várias espécies de bactérias, incluindo: Escherichia coli, Enterococcus faecalis, Staphylococcus aureus eepidermidis, Vibrio cholerae, Pseudomonas aeruginosa, Shigella flexneri, Bacillus anthracis, subtilis e cereus, Proteus mirabilis, Salmonella enterica typhimurium, Micrococcus luteus, Listeria monocytogenes e Klebsiella pneumoniae. Além disso, os compostos com prata são tóxicos para os fungos, como por exemplo, Candida albicans e Aspergillus niger ${ }^{[31]}$. Sachês de celulose, contendo AgNP geradas a partir de íons de prata in situ, têm sido utilizados para reduzir os níveis microbianos de exsudato de carne armazenada em embalagem de atmosfera modificada ${ }^{[33]}$.

Fernandez et al. ${ }^{[34]}$ também armazenaram cortes de melão fresco em filmes de base celulósica incorporado com AgNP e obtiveram baixas contagens microbianas (mesófilos, psicrófilos e leveduras) em comparação aos filmes controle (sem adição de AgNP). Além disso, as partículas de prata reduziram a concentração do gás etileno e os frutos armazenados na presença de AgNP estenderam seu tempo de maturação, aumentando sua validade comercial.

Partículas de $\mathrm{TiO}_{2}$ também são promissoras. Ao contrário dos compostos de prata, a atividade antimicrobiana das nanopartículas de $\mathrm{TiO}_{2}$ ocorre via fotocatálise e, por isto, antimicrobianos baseados $\mathrm{emTiO}_{2}$ são ativos apenas na 
presença da luz UV. As nanopartículas de $\mathrm{TiO}_{2}$ são eficazes contra patógenos de origem alimentar, como, S. choleraesuis, V. parahaemolyticus, e L. Monocytogenes sob radiação UV, mas não no escuro ${ }^{[9]}$. Chawengkijwanich ${ }^{[35]}$, demonstrou que embalagens de alimentos com filmes de PP revestidos com nanopartículas de $\mathrm{TiO}_{2}$ inibiram o crescimento de E. coli em alface fresca.

Em princípio, filmes para embalagens de alimentos que incorporam nanopartículas de $\mathrm{TiO}_{2}$ podem ter o benefício adicional de proteger os componentes de alimentos dos efeitos oxidantes da radiação UV e manter boa claridade óptica, pois as nanopartículas de $\mathrm{TiO}_{2}$ são eficientes nestes comprimentos de onda. Outro estudo verificou que o suco de laranja armazenado a $4{ }^{\circ} \mathrm{C}$, em filmes incorporados com P105 (mistura de $\mathrm{TiO}_{2}$ e nanopartículas de prata $(10 \mathrm{~nm})$ ) apresentou redução significativa no desenvolvimento de Lactobacillus plantarum $^{[30]}$.

Tang et al. ${ }^{[29]}$ também relataram que nanopartículas de óxido de magnésio (MgO), na concentração de 100 ppm, promoveram a redução de $1 \log$ de L. plantarum, após 24 horas de exposição, indicando ser um potencial material para a utilização como antimicrobiano em embalagens.

Alguns estudos demonstraram efeito antibacteriano de nanopartículas de óxido de zinco $(\mathrm{ZnO})$ sobre Campylobacter jejuni, através da investigação da sua inibição e a inativação do desenvolvimento celular. Os resultados demonstraram que o $C$. jejuni foi extremamente sensível ao tratamento com nanopartículas de $\mathrm{ZnO}$. Além disso, concluiu-se que a ação das nanopartículas de $\mathrm{ZnO}$ foi determinada como bactericida e não bacteriostática ${ }^{[36]}$.

Baek et al. ${ }^{[37]}$ estudaram a toxicidade de diversas nanopartículas de metais, dentre elas: óxido de cobre $(\mathrm{CuO})$, óxido de níquel (NiO), óxido de zinco $(\mathrm{ZnO})$, e trióxido de antimônio $\left(\mathrm{Sb}_{2} \mathrm{O}_{3}\right)$ frente a cepas de E. coli, B. subtilis e $S$. aureus, e verificaram que todos os tipos de nanopartículas apresentaram algum efeito tóxico, sendo o $\mathrm{CuO}$ o de maior expressão. Desta forma, a utilização destas nanopartículas em embalagens alimentícias seria uma ferramenta para a manutenção da segurança microbiológica nos alimentos acondicionados.

\subsection{Embalagens bioativas: incorporando compostos bioativos capazes de prevenir ou reduzir riscos de doenças}

O termo "embalagens bioativas" tem sido utilizado, genericamente, como referência a embalagens que interagem de forma desejável com o alimento e apresentam em sua composição polímeros de origem biológica ou natural. As nanodispersões e nanocápsulas são os mecanismos ideais para o carreamento destes ingredientes funcionais ${ }^{[38,39]}$. A tecnologia de incorporação destas substâncias em pequenas vesículas ou materiais com paredes em nano escala, é o que chamamos de nanoencapsulação. Estes novos nanomateriais oferecem diversas vantagens, como sistema de entrega de compostos lipofílicos, proteção contra degradação durante o processamento ou durante a passagem pelo trato gastrintestinal, controle da liberação em local específico, maior compatibilidade com outros componentes de alimentos, maior absorção, proteção de compostos bioativos como vitaminas, antioxidantes, proteínas e lipídeos.
Lopez-Rubio et al. ${ }^{[40]}$ propuseram uma nova abordagem para os sistemas de liberação com nanodispersões e nanoencapsulamento, associados aos materiais de embalagens. Nesta nova concepção, as embalagens bioativas ou funcionais seriam, mais precisamente, materiais de embalagem que retém princípios bioativos desejáveis em condições ótimas, até a sua eventual migração para o produto alimentício.

Assim, a principal diferença entre as conhecidas tecnologias de embalagens ativas e a concepção de bioativas deve-se principalmente à manutenção da qualidade e/ou aumento da segurança dos alimentos embalados, podendo estender a validade comercial de produtos alimentícios, no primeiro caso, enquanto que as embalagens bioativas têm um impacto direto na saúde do consumidor, através da geração de alimentos embalados mais saudáveis.

Estes novos sistemas híbridos de embalagem e atividade funcional, possibilitam a inclusão de prebióticos, probióticos, fitoquímicos, óleos marinhos, alimentos sem lactose e vitaminas encapsuladas, que visam proporcionar uma alternativa mais eficiente em fornecer alimentos com segurança e com características benéficas a saúde humana.

Ainda neste contexto de fornecer alimentos embalados mais saudáveis, há relatos da imobilização de enzimas específicas, que catalisam reações, produzindo resultados considerados benéficos do ponto de vista nutricional, por exemplo, ao diminuir a concentração de um constituinte alimentar não-desejado e/ou produzir uma substância alimentar benéfica para a saúde do consumidor. Com relação ao descrito, pode ser citado para incorporação em filmes de embalagens as enzimas $\beta$-galactosidase e a lactase, que hidrolisam a lactose presente no leite; e a colesterol-redutase a fim de hidrolisar o colesterol ${ }^{[41,42]}$. Neste contexto, o leite UHT convencional poderia ser acondicionado e armazenado em embalagens contendo estas enzimas hidrolíticas imobilizadas, e após um período de atividade enzimática, este leite poderia ser considerado com baixos níveis ou livre de lactose.

\subsection{Embalagens inteligentes: incorporadas com Nanosensores para monitorar e relatar as condições dos alimentos}

Os nanosensores podem ser colocados diretamente no material de embalagem, atuando como "língua eletrônica" ou "nariz" para detecção de substâncias químicas liberadas durante a deterioração dos alimentos ${ }^{[43]}$. Baseados em nanotecnologia, eles têm o potencial de revolucionar a velocidade e a precisão com que as indústrias ou agências reguladoras serão capazes de detectar a presença de contaminantes moleculares ou adulterantes em matrizes alimentares complexas. Muitos destes ensaios são baseados em alterações de cor que ocorrem nas soluções de nanopartículas de metal na presença de analitos. Por exemplo, as nanopartículas de ouro (AuNPs), funcionalizadas com grupos de ácido cianúrico, ligam-se seletivamente a melamina, um adulterante usado para aumentar, artificialmente, o teor proteico medido em alimentos para animais e fórmulas para lactentes. A agregação induzida da melamina com as AuNPs altera a cor do vermelho para o azul, podendo ser usada para medir com precisão o teor de melamina no leite cru e em fórmulas infantis em concentrações tão baixas como $2,5 \mathrm{ppb}$ a olho $\mathrm{nu}^{[44]}$. 
Um sensor, baseado em uma metodologia de detecção chamada de imuno-ensaio, ligado a fluorescência, pode ser usado para detectar a presença de gliadina, uma das principais proteínas de alimentos que causam a inflamação em pacientes que sofrem de doença celíaca. Este sistema utiliza a fluorescência em metal, a partir de anticorpos anti-gliadina associados a filmes nanoestruturados de prata, para determinar o teor de glúten, em alimentos livres de glúten, e poderia ser facilmente adaptado para a detecção seletiva de outros analitos à base de proteínas ${ }^{[45]}$.

Outro ensaio, baseado na detecção por fluorescência, é a verificação de teores de cianeto na água potável em baixas concentrações, utilizando supressão de fluorescência de $\mathrm{AuNPS}^{[46]}$. Várias toxinas bacterianas de origem proteica, incluindo a toxina botulínica sorotipo A, foram detectadas, em níveis picomolar $\left(10^{-12} \mathrm{M}\right)$, utilizando anticorpos luminescentes marcados com pontos quânticos, o que seria útil em aplicações anti-bioterrorismo ${ }^{[47]}$. A literatura relata imunossensores elétricos desenvolvidos para detectar a presença de aflatoxina-B17 em amostras de leite contaminado, até uma concentração de $0,01 \mathrm{ng} / \mathrm{mL}^{[48]}$. Estes nanosensores se baseiam na detecção eletroquímica e operam através da ligação de anticorpos seletivos com um nanomaterial condutor (por exemplo, nanotubos de carbono) e, em seguida, as mudanças de condutividade do material são monitoradas, quando o analito-alvo se liga aos anticorpos.

Um sensor de teor de umidade, baseado em nanopartículas de cobre revestidas de carbono dispersas numa película de tensoativo, foi desenvolvido por Luechinger et al. ${ }^{[49]}$. Em ambientes úmidos, o intumescimento da matriz polimérica resulta em maior grau de separação inter-nanopartículas. Essa mudança causa o estiramento dos sensores a fim de refletirem ou absorverem diferentes espectros de luz, que podem ser facilmente monitorados na determinação rápida e precisa dos níveis de umidade das embalagens.

\subsection{Toxicidade relacionada aos Nanos}

A nanotecnologia tem provocado preocupação e muitos debates. Alguns nanomateriais como: nanotubos de carbono e nanopartículas de prata, óxido de silício, óxido de alumínio, dióxido de titânio, e zinco podem resultar em imprevisíveis problemas de segurança e de risco para a saúde humana. Existe uma preocupação com a inalação de nanopartículas, pois devido ao fato das partículas serem muito pequenas, elas vencem barreiras naturais do aparelho respiratório, sendo depositadas e acumuladas nos alvéolos pulmonares, responsáveis pela troca gasosa de oxigênio e gás carbônico com a corrente sanguínea ${ }^{[50]}$. Quando inaladas, nanopartículas de dióxido de titânio podem alcançar os pulmões podendo ficar acumuladas neste órgão e provocar doenças crônicas, como inflamação pulmonar, pneumonia entre outras ${ }^{[9]}$.

A forma como as nanopartículas entram no corpo humano, os sítios de penetração, o possível acúmulo e a translocação das mesmas, no corpo, também podem determinar um potencial de risco ${ }^{[51]}$.

Segundo Schulte et al. ${ }^{[52]}$ as empresas que trabalham com nanotecnologia e que não possuem total conhecimento sobre os efeitos da exposição às nanopartículas devem orientar seus funcionários sobre os riscos e controles já estabelecidos.
Assim será possível selecionar e implementar controles preventivos em relação a toxicidade destas partículas.

Três vias de exposição aos nanomateriais podem ser consideradas em humanos: inalação sendo a rota principal para os trabalhadores em laboratórios e indústrias; ingestão sendo a via predominante para a população em geral, e pode ocorrer de forma indireta por meio da migração de nanomaterias das embalagens para os alimentos; e absorção pelo contato com a pele, por meio da utilização de cosméticos ${ }^{[53]}$. A ingestão de nanopartículas pode ainda ocorrer de forma involuntária, por meio do consumo de água proveniente de aparelhos de purificação que utilizam nanomateriais filtrantes ou desinfetantes, além da ingestão de alimentos que tiveram contato prolongado com utensílios contendo, por exemplo, nanopartículas de prata. Apesar desta possibilidade, estudos consideram que a ingestão deve ser pequena em termos de massa ${ }^{[50]}$. Quando ingerida por meio de água, medicamentos ou alimentos, as nanopartículas podem penetrar na barreira de muco intestinal, de forma que quanto menor a partícula, mais rápida sua absorção ${ }^{[54]}$.

Como existe a preocupação com a exposição indireta de nanopartículas com alimentos, se faz necessário conhecer a extensão de migração das nanopartículas da embalagem para os produtos e, caso ocorra a migração, quais serão os efeitos da ingestão destas nanopartículas no corpo humano. São poucos os estudos sobre migração de nanopartículas de embalagens para os alimentos, logo torna-se difícil avaliar o risco para o consumidor, embora, uma cuidadosa avaliação da natureza dos materiais e a aplicação a que se destina possa fornecer uma base para a classificação dos possíveis riscos de forma individual ${ }^{[55]}$.

Para determinar a toxicidade das embalagens compostas por nanopartículas muitos parâmetros devem ser analisados, tais como: tamanho da nanopartícula, forma, solubilidade, composição química entre outros fatores físico-químicos. A avaliação de risco é realizada para identificar e quantificar os $\operatorname{riscos}{ }^{[55]}$.

Numerosos estudos realizados in vitro e in vivo (ratos e camundongos), mostram um grande número e uma ampla variedade de efeitos adversos graves como: atraso no crescimento, malformações, alterações no desenvolvimento e/ou na reprodução, modificações genéticas e efeitos cancerígenos $^{[50]}$. É muito provável que as propriedades toxicológicas possam variar entre os nanomateriais, assim a avaliação de risco sempre deve ser realizada de forma isolada ${ }^{[56]}$. A toxicidade de uma substância nova é estudada com testes toxicológicos orais, toxicidade cutânea, bem como testes de mutagenicidade que são realizados em células ${ }^{[57]}$. Tanto os benefícios quanto os riscos devem ser transmitidos ao público, e deve ficar claro para os consumidores se os benefícios superam os riscos e se estes riscos são aceitáveis. Muitas incertezas permanecem a respeito dos efeitos das nanopartículas sobre a saúde, por isso, as pesquisas devem ter continuidade para investigar sua possível toxicidade.

\subsection{Regulamentação da Nanotecnologia em embalagens de alimentos}

Com o avanço da utilização da nanotecnologia, pode haver um aumento potencial de fontes indiretas e diretas de contaminação de alimentos, através do contato com as 
nanopartículas. A migração de nanopartículas da embalagem para o alimento ainda não pode ser considerada significativa, devido a poucos estudos desenvolvidos neste setor. Desta forma, não há diretrizes específicas para a nanotecnologia aplicada a embalagens, onde, na maioria dos casos, utilizam-se legislações já vigentes de migração, de maneira geral, de compostos presentes em embalagens plásticas ${ }^{[58]}$.

No Brasil, a RDC n 51 de 26 de novembro de 2010 estabelece os critérios de migração para materiais, embalagens e equipamentos plásticos destinados ao contato com alimentos, bem como os simulantes de alimentos para caracterização do tipo de embalagem destinada a cada produto, considerando-se suas características físico-químicas e de processamento ${ }^{[59]}$. O Ministério da Ciência, Tecnologia e Inovação, criou a Portaria $\mathrm{n}^{\circ} 245$ em 05 de abril de 2012, que institui Sistema Nacional de Laboratórios em Nanotecnologias SisNano como um dos elementos do Programa Nacional de Nanotecnologia, no âmbito da Estratégia Nacional de Ciência, Tecnologia e Inovação. Esses laboratórios têm como objetivos principais a estruturação da governabilidade para as nanotecnologias, promover uma maior disponibilidade do conhecimento, bem como desenvolver cada vez mais pesquisas neste setor, de forma a promover o avanço científico e tecnológico do país ${ }^{[60]}$. Existe, ainda, o Projeto de Lei ${ }^{o} 5133 / 13^{[53]}$ do Deputado Sarney Filho, que visa regulamentar a rotulagem de produtos desenvolvidos por processos nanotecnológicos e de produtos que fazem uso da nanotecnologia, criando exigências para que o consumidor seja informado que determinada embalagem de alimentos contém nanocompostos em sua formulação. De acordo com esse projeto as embalagens devem conter um símbolo que identifique a presença de produto ou processo nanotecnológico. Além disso, as embalagens dos produtos devem conter, em destaque, uma das seguintes expressões: (nome do produto) obtido por processo nanotecnológico; ou (nome do ingrediente ou ingredientes) nanotecnológico(s). A proposta encontra-se em análise das comissões de Desenvolvimento Econômico, Indústria e Comércio; de Defesa do Consumidor; de Constituição e Justiça e de Cidadania ${ }^{[53]}$.

Para a União Européia, por exemplo, o quesito segurança está diretamente vinculado com os produtos químicos que podem migrar da matriz da embalagem para os alimentos. Essas embalagens devem ser fabricadas de acordo com os seus regulamentos, incluindo as Boas Práticas de Fabricação, de forma que qualquer transferência não levante preocupações de segurança, não altere a composição dos alimentos de uma forma inaceitável ou tenha efeitos adversos de sabor/odor ${ }^{[61]}$. A Diretiva 82/711/CEE estabelece as regras de base necessárias à verificação da migração dos constituintes de embalagens para alimentos e a Diretiva 85/572/CEE lista os simulantes para avaliar a migração dos componentes dos materiais plásticos ${ }^{[58,62,63]}$.

$\mathrm{Na}$ Europa o uso de nanopartículas em alimentos ou em contato com alimentos, deve ser precedido da avaliação pela European Food Safety Agency (EFSA) e ser submetido à Diretiva 1333/2008 como novo aditivo, ainda que a mesma partícula na escala convencional já tenha sido aprovada ${ }^{[64,65]}$. Para embalagens de alimentos, atualmente, apenas três nanomateriais foram autorizados: o negro de carbono, o nitreto de titânio e dióxido de silício. Porém, o nitreto de titânio não pode ser detectável em alimentos, o negro de fumo não pode ser utilizado em níveis superiores a 2,5\% $\mathrm{m} / \mathrm{m}$ de embalagens e para o dióxido de silício o limite de migração específica ainda não foi definido ${ }^{[66]}$.

Nos Estados Unidos o Food and Drug Administration (FDA) ainda não estabeleceu definições sobre nanomaterial, escala nanométrica, ou outros termos relacionados ${ }^{[66,67]}$. A agência mantém a posição de que os materiais quimicamente idênticos a um aditivo indireto autorizado em alimentos ou uma substância reconhecida como segura (GRAS), que respeite os limites especificados, podem ser utilizados sem aviso prévio ${ }^{[68]}$. Como, por exemplo, o alumínio e a argila bentonita, pela melhoria nas propriedades de barreira, a prata pela atividade antimicrobiana e o óxido de zinco pela propriedade de barreira UV e atividade antimicrobiana. Tais materiais são classificados como GRAS, portanto poderiam ser utilizados, pois, não há na legislação nenhuma menção referente ao tamanho da partícula ${ }^{[69]}$.

O FDA ainda não definiu se os produtos que envolvem aplicações nanotecnológicas são benignos ou prejudiciais ${ }^{[6]}$. A agência mantém uma política regulatória de base científica focada no produto, e afirma que estudos científicos que comprovem o risco ou ausência de risco de um produto com aplicações nanotecnológicas são necessários para embasar uma norma regulamentadora. As avaliações técnicas futuras serão específicas, levando em consideração os efeitos biológicos de um dado nanomaterial e seu uso pretendido ${ }^{[70]}$.

\section{Conclusões}

O conhecimento sobre os materiais em nanoescala, bem como seu comportamento tem surgido de forma relativamente lenta. O principal fator limitante é o grau de conhecimento de pesquisadores, engenheiros e reguladores, que ainda permanecem despreparados para gerenciar os riscos dos nanomateriais e seus produtos de degradação ao meio ambiente e a saúde humana. Por esta razão, esta é uma questão que ainda permanece em aberto e representa um dos desafios para a regulamentação da nanotecnologia aplicada em produtos que estarão em contato direto com alimentos. As vantagens desta nova tecnologia são indiscutíveis, no entanto é fundamental esclarecer a todas as partes envolvidas (consumidores, pesquisadores, trabalhadores, produtores e reguladores) a respeito das incertezas e riscos associados ao uso da nanotecnologia, embora estes ainda não sejam totalmente conhecidos.

\section{Referências}

1. Davis, G. \& Song, J. H. (2006). Biodegradable packaging based on raw materials from crops and their impact on waste management. Industrial Crops and Products, 23(2), 147-161. http://dx.doi.org/101016/j.indcrop.2005.05.004.

2. Rabello, M. (2000). Aditivação de polímeros. São Paulo: Editora Artiliber.

3. Alexandre, M., \& Dubois, P. (2000). Polymer-layered silicate nanocomposites: preparation, properties and uses of a new class of materials. Materials Science and Engineering, 28(1-2), 1-63. http://dx.doi.org/10.1016/S0927-796X(00)00012-7.

4. Espitia, P., Soares, N. F., Coimbra, J. S. R., Andrade, N. J., Cruz, R. S., \& Medeiros, E. A. A. (2012). Zinc oxide nanoparticles: Synthesis, antimicrobial activity and food packaging applications. 
Food and Bioprocesses Technology, 5(5), 1447-1464. http:// dx.doi.org/10.1007/s11947-012-0797-6.

5. International Organization for Standardization - ISO. (2010). ISO/TS80004-1: nanotechnologies - vocabulary. Part 1: core terms. Geneva: ISO. Recuperado em 12 de julho de 2014, de https://www.iso.org/obp/ui/\#iso:std:iso:ts:80004:-1:ed-1:v1:en.

6. Vert, M., Doi, Y., Karl-Heinz, H., Hess, M., Hodge, P., Kubisa, P., Rinaudo, M., \& Schué, F. (2012). Terminology for biorelated polymers and applications (IUPAC Recommendations 2012). Pure and Applied Chemistry, 84(2), 377-410. http://dx.doi. org/10.1351/PAC-REC-10-12-04.

7. US FOOD AND DRUG ADMINISTRATION. (2012). Nanotechnology: silver spring: FDA. Recuperado em 25 de agosto de 2014, de http://www.fda.gov/ScienceResearch/ SpecialTopics/Nanotechnology/default.html.

8. Carr, G. L. (2007). Desenvolvimento de Embalagem biodegradável tipo espuma a partir de fécula de mandioca (Tese de doutorado). Universidade de São Paulo, São Paulo. Recuperado em 09 de julho de 2014, de http://www.teses.usp. br/teses/disponiveis/3/3137/tde-08012008-150706/pt-br.php.

9. Kim, B., Kim, D., Cho, D., \& Cho, S. (2003). Bactericidal effect of TiO2 photocatalyst on selected food-borne pathogenic bacteria. Chemosphere, 52(1), 277-281. http://dx.doi.org/10.1016/ S0045-6535(03)00051-1. PMid:12729712.

10. Podsiadlo, P., Choi, S. Y., Shim, B., Lee, J., Cuddihy, M., \& Kotov, N. A. (2005). Molecularly engineered nanocomposites: layer-bylayer assembly of cellulose nanocrystals. Biomacromolecules, 6, 2914-2918. http://dx.doi.org/10.1021/bm050333u.

11. Drexler, K. E. (2004). Nanotechnology: From Feynman to Funding. Bulletin of Science, Technology \& Society, 24(1), 21-27. http://dx.doi.org/10.1177/0270467604263113.

12. Zhou, Q., Pramoda, K. P., Lee, J. M., Wang, K., \& Loo, L. S. (2011). Role of interface in dispersion and surface energetics of polymer nanocomposites containing hydrophilic POSS and layered silicates. Journal of Colloid and Interface Science, 355(1), 222-230. http://dx.doi.org/10.1016/j.jcis.2010.12.010. PMid:21190693.

13. Silvestre, C., Duraccio, D., \& Cimmino, S. (2011). Food packaging based on polymer nanomaterials. Progress in Polymer Science, 36(12), 1766-1782. http://dx.doi.org/10.1016/j. progpolymsci.2011.02.003.

14. Finnigan, B. (2009). Barrier polymers. In: K. L. Yam (Ed.), The wiley encyclopedia of packaging technology (pp. 103-109). New York: John Wiley and Sons.

15. Chau, C. F., Wu, S. H., \& Yen, G. C. (2007). The development of regulations for food nanotechnology. Trends in Food Science \& Technology, 18(5), 269-280. http://dx.doi.org/10.1016/j. tifs.2007.01.007.

16. Sanchez-Garcia, M. D., Gimenez, E., \& Lagaron, J. M. (2008). Morphology and barrier properties of solvent cast composites of thermoplastic biopolymers and purified cellulose fibers. Carbohydrate Polymers, 71(2), 235-244. http://dx.doi. org/10.1016/j.carbpol.2007.05.041.

17. Arrieta, M. P., Fortunati, E., Dominici, F., Rayón, E., López, J., \& Kenny, J. M. (2014). Multifunctional PLA-PHB/cellulose nanocrystal films: processing,structural and thermal properties. Carbohydrate Polymers, 107, 16-24. http://dx.doi.org/10.1016/j. carbpol.2014.02.044. PMid:24702913.

18. Mirzadeh, A., \& Kokabi, M. (2007). The effect of composition and draw-down ratio on morphology and oxygen permeability of polypropylene nanocomposite blown films. European Polymer Journal, 43(9), 3757-3765. http://dx.doi.org/10.1016/j. eurpolymj.2007.06.014.

19. Park, H. M., Lee, W. K., Park, C. Y., Cho, W. J., \& Ha, C. S. (2003). Environmentally friendly polymer hybrids: part 1. Mechanical, thermal, and barrier properties of the thermoplastic starch/clay nanocomposites. Journal of Materials Science, 38(5), 909-915. http://dx.doi.org/10.1023/A:1022308705231.

20. Hu, Q., Fang, Y., Yang, Y., Ma, N., \& Zhao, L. (2011). Effect of nanocomposite-based packaging on postharvest quality of ethylene-treatedkiwifruit (Actinidiadeliciosa) during cold storage, China. Food Research International, 44(6), 1589-1596. http://dx.doi.org/10.1016/j.foodres.2011.04.018.

21. Wong, Y. W. H., Yuen, C. W. M., Leung, M. Y. S., Ku, S. K. A., \& Lam, H. L. I. (2006). Selected applications of nanotechnology in textiles. AUTEX Research Journal, 6(1), 1-8. Recuperado 09 de julho de 2014, de http://www.autexrj. com/cms/zalaczone_pliki/1-06-1.pdf.

22. Lahtinen, K., Maydannik, P., Seppänen, T., Cameron, C. D. C., Johansson, P., Kotkamo, S., \& Kuusipalo, J. (2013). Protecting BOPP film from UV degradation with an atomic layer deposited titanium oxide surface coating, Finland. Applied Surface Science, 282, 506-511. http://dx.doi.org/10.1016/j. apsusc.2013.06.002.

23. Chaleshtori, M. Z., Masud, S. M. S., \& Saupe, G. B. (2008). Using new porous nanocomposites for photocatalytic water decontamination. Materials Research Society Symposium Proceedings, 1145, 75-80. http://dx.doi.org/10.1557/PROC1145-MM04-36.

24. Kim, J. Y., Han, S., \& Hong, S. (2008). Effect of modified carbon nanotube on the properties of aromatic polyester nanocomposites. Polymer, 49(15), 3335-3345. http://dx.doi. org/10.1016/j.polymer.2008.05.024.

25. Shan, G. F., Gong, X., Chen, W. P., Chen, L., \& Zhu, M. F. (2011). Effect of multi-walled carbon nanotubes on crystallization behavior of poly(3-hydroxybutyrate-co-3-hydroxyvalerate). Colloid \& Polymer Science, 289(9), 1005-1014. http://dx.doi. org/10.1007/s00396-011-2412-1.

26. Xu, C., \& Qiu, Z. (2011). Crystallization behavior and thermal property of biodegradable poly(3-hydroxybutyrate)/multi-walled carbon nanotubes nanocomposite. Polymers for Advanced Technologies, 22(5), 538-544. http://dx.doi.org/10.1002/ pat. 1540 .

27. Yu, H. Y., Qin, Z. Y., Sun, B., Yang, X. G., \& Yao, J. M. (2014). Reinforcement of transparent poly(3-hydroxybutyrate-co-3 hydroxyvalerate) by incorporation of functionalized carbon nanotubes as a novel bionanocomposite for food packaging. Composites Science and Technology, 94, 96-104. http://dx.doi. org/10.1016/j.compscitech.2014.01.018.

28. Huang, J., \& Rodrigue, D. (2014). The effect of carbon nanotube orientation and content on the mechanical properties of polypropylene based composites. Materials \& Design, 55, 653-663. http://dx.doi.org/10.1016/j.matdes.2013.10.039.

29. Tang, Z. X., Fang, X. J., Zhang, Z. L., Zhou, T., Zhang, X. Y. \& Shi, L. E. (2012). Nanosize MgO as antibacterial agent: preparation and characteristics. Brazilian Journal of Chemical Engineerig, 29(4), 775-781. http://dx.doi.org/10.1590/S010466322012000400009 .

30. Emamifar, A., Kadivar, M., Shahedi, M., \& Soleimanian-zad, S. (2011). Effect of nanocomposite packaging containing $\mathrm{Ag}$ and $\mathrm{ZnO}$ on inactivation of Lactobacillus plantarum in orange juice. Food Control, 22(3-4), 408-415. http://dx.doi. org/10.1016/j.foodcont.2010.09.011.

31. Gogoi, S. K., Gopinath, P., Paul, A., Ramesh, A., Ghosh, S. S., \& Chattopadhyay, A. (2006). Green fluorescent proteinexpressing Escherichia coli as a model system for investigating the antimicrobial activities of silver nanoparticles. Langmuir, 22(22), 9322-9328. http://dx.doi.org/10.1021/la060661v. PMid: 17042548.

32. Duncan, T. V. (2011). Applications of nanotechnology in food packaging and food safety: Barrier materials, antimicrobials and 
sensors. Journal of Colloid and Interface Science, 363(1), 1-24. http://dx.doi.org/10.1016/j.jcis.2011.07.017. PMid:21824625.

33. Fernandez, A., Picouet, P., \& Lloret, E. (2010). Reduction of the spoilage-related microflora in absorbent pads by silver nanotechnology during modified atmosphere packaging of beef meat. Journal of Food Protection, 73(12), 2263-2269. PMid:21219746.

34. Fernandez, A., Picouet, P., \& Lloret, E. (2010). Cellulosesilver nanoparticle hybrid materials to control spoilage-related microflora in absorbent pads located in trays of fresh-cut melon. International Journal of Food Microbiology, 142(1-2), 222-228. http://dx.doi.org/10.1016/j.ijfoodmicro.2010.07.001. PMid:20656367.

35. Chawengkijwanich, C., \& Hayata, Y. (2008). Development of $\mathrm{TiO} 2$ powder-coated food packaging film and its ability to inactivate Escherichia coli in vitro and in actual tests. International Journal of Food Microbiology, 123(3), 288292. http://dx.doi.org/10.1016/j.ijfoodmicro.2007.12.017. PMid: 18262298 .

36. Xie, Y., He, Y., Irwin, L. P., Jin, T., \& Shi, X. (2011). Antibacterial activity and mechanism of action of zinc oxide nanoparticles against campylobacter jejuni. Applied and Environmental Microbiology, 77(7), 2325-2331. http://dx.doi.org/10.1128/ AEM.02149-10. PMid:21296935.

37. Baek, Y. W., \& An, Y. J. (2011). Microbial toxicity of metal oxide nanoparticles $(\mathrm{CuO}, \mathrm{NiO}, \mathrm{ZnO}$, and $\mathrm{Sb} 2 \mathrm{O} 3)$ to Escherichia coli, Bacillus subtilis, and Streptococcus aureus. The Science of the Total Environment, 409(8), 1603-1608. http://dx.doi. org/10.1016/j.scitotenv.2011.01.014. PMid:21310463.

38. Coma, V. (2008). Bioactive packaging technologies for extended shelf life of meat-based products. Meat Science, 78(1-2), 90-103. http://dx.doi.org/10.1016/j.meatsci.2007.07.035. PMid:22062099.

39. Assis, L. M., Zavareze, E. R., Prentice-Hernández, C. \& Souza-Soares, L. A. (2012). Características de nanopartículas e potenciais aplicações em alimentos. Brazilian Journal of Food Technology, 15(2), 99-109. http://dx.doi.org/10.1590/ S1981-67232012005000004.

40. Lopez-Rubio, A., Gavara, R., \& Lagaron, J. M. (2006). Bioactive packaging: turning foods into healthier foods through biomaterials. Trends in Food Science \& Technology, 17(10), 567-575. http://dx.doi.org/10.1016/j.tifs.2006.04.012.

41. Brody, A. L., \& Budney, J. A. (1995). Enzymes as active packing agents. In M. L. Roovey (Ed). Active food packing (pp. 174-192). Glasgow: Springer.

42. Cunha, L.R., Soares, N. F. F., Assis, F. C. C., Melo, N. R., Pereira, A. F. \& Silva, C. B. (2007). Desenvolvimento e avaliação de embalagem ativa com incorporação de lactase. Ciência e Tecnologia de Alimentos, 27, 23-26. http://dx.doi. org/10.1590/S0101-20612007000500004.

43. Sozer, N., \& Kokini, J. L. (2009). Nanotechnology and its applications in the food sector. Trends in Biotechnology, 27(2), 82-89. http://dx.doi.org/10.1016/j.tibtech.2008.10.010. PMid:19135747.

44. Ai, K., Liu, Y., \& Lu, L. (2009). Hydrogen-bonding recognitioninduced color change of gold nanoparticles for visual detection of melamine in raw milk and infant formula. Journal of the American Chemical Society, 131(27), 9496-9497. http://dx.doi. org/10.1021/ja9037017. PMid:19537721.

45. Staiano, M., Matveeva, E. G., Rossi, M., Crescenzo, R., Gryczynski, Z., Gryczynski, I., Iozzino, L., Akopova, I., \& D’Auria, S. (2009). Nanostructured silver-based surfaces: new emergent methodologies for an easy detection of analytes. ACS Applied Materials \& Interfaces, 1(12), 2909-2916. http:// dx.doi.org/10.1021/am900617p. PMid:20356174.
46. Liu, H., Xie, F., Yu, L., Chen, L., \& Li, L. (2009). Thermal processing of starch-based polymers. Progress in Polymer Science, 34(12), 1348-1368. http://dx.doi.org/10.1016/j. progpolymsci.2009.07.001.

47. Warner, M. G., Grate, J. W., Tyler, A., Ozanich, R. M., Miller, K. D., Lou, J., Marks, J. D., \& Bruckner-Lea, C. J. (2009). Quantum dot immunoassays in renewable surface column and 96-well plate formats for the fluorescence detection of botulinum neurotoxin using high-affinity antibodies. Biosensors \& Bioelectronics, 25(1), 179-184. http://dx.doi.org/10.1016/j. bios.2009.06.031. PMid:19643593.

48. Jin, X., Jin, X., Chen, L., Jiang, J., Shen, G., \& Yu, R. (2009). Piezoelectric immunosensor with gold nanoparticles enhanced competitive immunoreaction technique for quantification of aflatoxin B1. Biosensors \& Bioelectronics, 24(8), 2580-2585. http://dx.doi.org/10.1016/j.bios.2009.01.014. PMid:19237278.

49. Luechinger, N. A., Loher, S., Athanassiou, E. K., Grass, R. N., \& Stark, W. J. (2007). Highly sensitive optical detection of humidity on polymer/metal nanoparticle hybrid films. Langmuir, 23(6), 3473-3477. http://dx.doi.org/10.1021/ la062424y. PMid: 17279782 .

50. Paschoalino, M. P., Marcone, G. P. S. \& Jardim, W. F. (2010). Os nanomateriais e a questão ambiental. Química Nova, 33(2), 421-430. http://dx.doi.org/10.1590/S0100-40422010000200033.

51. Oberdorster, E., Zhu, S., Blickley, T. M., Mcclellan-Green, P., \& Haasch, M. L. (2006). Ecotoxicology of carbon-based engineered nanoparticles: effects of fullerene (C60) on aquatic organisms. Carbon, 44(6), 1112-1120. http://dx.doi. org/10.1016/j.carbon.2005.11.008.

52. Schlte, P. A. \& Salamanca-Buentello, F. (2007). As questões éticas e científicas da nanotecnologia no local de trabalho. Ciência \& Saúde Coletiva, 12(5), 1319-1332. http://dx.doi. org/10.1590/S1413-81232007000500030.

53. BRASIL. (2013, 13 de março). Projeto de Lei 5133/2013. Regulamenta a rotulagem de produtos da nanotecnologia e de produtos que fazem uso da nanotecnologia. Diário Oficial da República Federativa do Brasil, Brasília. Recuperado em 09 de dezembro de 2015. http://www2 .camara.leg.br/camaranoticias/ noticias/CIENCIA-E-TECNOLOGIA/448069-PROPOSTAREGULA-ROTULAGEM-DE-NANOMATERAIS.html.

54. Nel, A., Xia, T., Madler, L., \& Li, N. (2006). Toxic potential of materials at the nanolevel. Science, 311(5761), 622-627. http://dx.doi.org/10.1126/science.1114397. PMid:16456071.

55. Avella, M., De Vlieger, J. J., Errico, M. E., Fischer, S., Vacca, P., \& Volpe, M. G. (2005). Biodegradable starch/clay nanocomposite films for food packaging applications. Food Chemistry, 93(3), 467-474. http://dx.doi.org/10.1016/j.foodchem.2004.10.024.

56. Munro, I. C., Haighton, L. A., Lynch, B. S., \& Tafazoli, S. (2009). Technological challenges of addressing new and more complex migrating products from novel food packaging materials. Food Additives and Contaminants, 26(12), 1534-1546. http:// dx.doi.org/10.1080/02652030902995277. PMid:19938328.

57. Cui, D., Tian, F., Ozkan, C. S., Wang, M., \& Gao, H. (2005). Effect of single wall carbon nanotubes on human HEK293 cells. Toxicology Letters, 155(1), 73-85. http://dx.doi.org/10.1016/j. toxlet.2004.08.015. PMid:15585362.

58. Chaudhry, Q., Scotter, M., Blackburn, J., Ross, B., Boxall, A., Castle, L., Aitken, R., \& Watkins, R. (2008). Applications and implications of nanotechnologies for the food sector. Food Additives \& Contaminants: Part A, 25(3), 241-258. http:// dx.doi.org/10.1080/02652030701744538. PMid:18311618.

59. BRASIL. Agência Nacional de Vigilância Sanitária. (2010, 26 de novembro). Resolução no 51 de 26 de novembro de 2010. Dispõe sobre migração em materiais, embalagens e equipamentos plásticos a entrar em contato com alimentos. Diário Oficial da República Federativa do Brasil, Brasília. 
Recuperado em 23 de agosto de 2014, de http://portal.anvisa. gov.br/wps/portal/anvisa/anvisa/home.

60. BRASIL. Ministério da Ciência, Tecnologia e Inovação. (2012, 04 de abril). Portaria no 245 de 05 de abril de 2012. Instituição do Sistema Nacional de Laboratórios em Nanotecnologia. Diário Oficial da República Federativa do Brasil, Brasília. Seção I, p. 5.

61. European Food Safety Authority - EFSA. (2011). Guidance on the risk assessment of the application of nanoscienceand, nanotechnologies in the food and feed chain. The EFSA Journal, 9(5), 1-36. doi: http://dx.doi.org/10.2903/j.efsa.2011.2140.

62. Diretiva 82/711 CEE do Conselho. (1982, 18 de outubro). Estabelece as normas básicas necessárias para verificação da migração de constituintes dos materiais de embalagem e objetos de materiais plásticos destinados a entrar em contato com produtos alimentícios. Jornal Oficial das Comunidades Européias, Luxemburgo. p. 278-282. Recuperado em 23 de agosto de 2014, de http://eur-lex.europa.eu/legal content/PT/ TXT/HTML/?uri=CELEX:32006L0015\&from=PT.

63. Diretiva 85/572/CEE do Conselho. (1985, 19 de dezembro). Determina a lista dos simulantes que devem ser utilizados para controlar a migração de componentes dos materiais e objetos de materiais plásticos destinados a entrar em contato com produtos alimentícios. Jornal Oficial das Comunidades Européias, Bruxelas. p. 41-48. Recuperado em 23 de agosto de 2014, de http://eur-lex.europa.eu/legal-content/PT/TXT/ HTML/?uri=CELEX:31985L0572\&from=ES.

64. Food Safety Authority Of Ireland. (2015). Nanotechnologyand food. Recuperado em 10 de março de 2015, de https://www. fsai.ie/nanotechologyandfood.html.

65. European Commission - EU. (2008). Regulation (EC) no $1333 / 2008$ of the european parliament and of the council of
16 December 2008 on food additives. Recuperado em 10 de março de 2015, de http://eur-lex.europa.eu/legal-content/EN/ TXT/?uri=celex:32008R1333.

66. Commission Regulation - EU. (2011, 15 de janeiro). EU no 10/2011. On plastic materials and articles intended to come in contact with food. Official Journal of the European Union. Recuperado em 29 de março de 2015, de http://eur-lex.europa. eu/LexUriServ/LexUriServ.do?uri=CONSLEG:2011R0010:2 0111230:EN:PDF.

67. Food And Drug Administration - FDA. (2014). Guidance for industry considering whether an FDA-regulated product involves the application of nanotechnology. Contains Nonbinding Recommendations. Recuperado em 30 de março de 2015, de http://www.fda.gov/RegulatoryInformation/Guidances/ ucm257698.htm.

68. Food Packaging Forum. (2013). Food packaging regulation in the US. Recuperado em 30 de março de 2015, de http://www. foodpackagingforum.org/food-packaging-health/regulationon-food-packaging/food-packaging-regulation-in-the-us.

69. Food Packaging Forum. (2013). Nanomaterials. Recuperado em 30 de março de 2015, de http://www.foodpackagingforum. org/food-packaging-health/nanomaterials.

70. Food And Drug Administration - FDA. (2014). Guidance for industry: safety of nanomaterials in cosmetic products. Recuperado em 30 de março de 2015, de http://www.fda. gov/Cosmetics/GuidanceRegulation/GuidanceDocuments/ ucm300886.htm.
Enviado: Jan. 19, 2015

Revisado: Abr. 27, 2015

Aceito: Ago. 31, 2015 